\title{
Erythroplasia of Queyrat treated with topical 5-fluorouracil ${ }^{*}$
}

\author{
João Roberto Antônio ${ }^{1}$ \\ Lívia Arroyo Trídico ${ }^{1}$ \\ Ivan Rollemberg ${ }^{1}$
}

\author{
Carlos Roberto Antônio ${ }^{1}$ \\ Fernanda Tomé Alves ${ }^{1}$
}

DOI: http:/ / dx.doi.org/10.1590/abd1806-4841.20164595

\begin{abstract}
We report a 33-year-old male patient diagnosed with erythroplasia of Queyrat. The patient had an erythematous and eroded lesion affecting more than $50 \%$ of the glans associated with bleeding and local pain. Despite previous indication of penectomy, he was successfully treated with topical 5-fluorouracil.
\end{abstract}

Keywords: Carcinoma in Situ; Penis; Therapeutics

\section{INTRODUCTION}

Erythroplasia of Queyrat (EQ) is a rare in situ squamous cell carcinoma (SCC) of the glans penis, which typically appears as one or more well-marginated erythematous velvety plaques. ${ }^{1}$ Its cause is still unknown. ${ }^{2}$ It affects almost exclusively uncircumcised young men. Predisposing factors include lack of hygiene, smegma, humidity, and heat. ${ }^{3}$ For this reason, early circumcision is considered an appropriate preventive measure for male patients. ${ }^{3}$ The role of human papillomavirus (HPV) - oncogenic types $8,39,51$, and mostly 16 - was recently proposed in its pathogenesis. ${ }^{4}$ Studies estimate progression to invasive SCC in a third of patients.

Histopathological examination (hematoxylin-eosin stain) shows identical results to Bowen's disease. However, the epidemiology and anatomical location of these two conditions are mutually exclusive. ${ }^{5}$ Similar to Bowen's disease (BD), the presence of infiltration, nodularity, and/or ulceration often suggests a possible conversion to an invasive squamous cell carcinoma. ${ }^{6}$

As EQ has a strong tendency to develop into invasive penile carcinoma and treatment options include tissue removal - either by invasive techniques, such as partial or total penectomy, or through noninvasive techniques, such as laser ablation, cryosurgery, photodynamic therapy, topical 5-fluorouracil, and imiquimod 5\%. ${ }^{1,2}$ When selecting the most appropriate therapy, it is important to accurately determine, by means of biopsy, whether the patient has EQ or invasive SCC. ${ }^{7}$
The removal of cancer by partial or total penectomy is a standard therapy, but these radical procedures can cause considerable mental distress, including suicide. Therefore, the development of a non-invasive alternative treatment for EQ is essential. We report the case of an EQ patient with penectomy indicated by an urologist, but who responded well to topical treatment with topical 5-fluorouracil.

\section{CASE REPORT}

We report a 33-year-old male patient present to our institution with a history of having performed circumcision for about eight years due to an eroded lesion on the distal glans treated with antibiotics and topical corticosteroids without improvement. The patient reported that the lesion had been persistent for eight years and had recently increased in size. Local pain and possible bleeding were also reported. The patient had gone through prior consultation with a urologist who suggested radical excision of the tip of the glans.

Dermatological physical examination revealed eroded erythematous flat lesions, with sharp and regular edges, affecting more than $50 \%$ of the glans (Figure 1). We observed no inguinal lymphadenopathy. General physical examination was normal.

An incisional biopsy showed proliferation of atypical keratinocytes in the epidermis, with perivascular lymphocytic infiltrate in the adjacent dermis compatible with EQ (Figure 2).

\section{Received on 28.03.2015}

Approved by the Advisory Board and accepted for publication on 09.05.2015

Work performed at Faculdade de Medicina de São José do Rio Preto (FAMERP) - São José do Rio Preto (SP), Brazil.

Financial Support: None.

Conflict of Interest: None

1 Faculdade de Medicina de São José do Rio Preto (FAMERP) - São José do Rio Preto (SP), Brazil.

C2016 by Anais Brasileiros de Dermatologia 
Given this diagnosis and the patient's age, we chose to perform a nonsurgical treatment with topical 5-fluorouracil 5\%. Initially, 5-fluorouracil 5\% was applied to the entire lesion twice daily for two weeks. We obtained a favorable result fifteen days after the application, considering the initial irritation predicted with the use of this medication (Figure 3). We repeated two more cycles of treatment for two weeks, with an interval of fifteen days between the cycles (Figure 4). Thirty days after the third cycle, the lesion showed complete clinical resolution, displaying only discreet erythema at the distal glans. Two months after the third cycle, we performed a biopsy that showed standard lichenoid interface dermatitis with no atypical cells in the epidermis (Figure 5).

Thus, we decided to monitor the patient monthly. Six months after the treatment, physical examination revealed only a scar in the lesion site (Figure 6). One year after the treatment, the patient showed no recurrence, progressing to complete healing and maintaining continuous follow up.

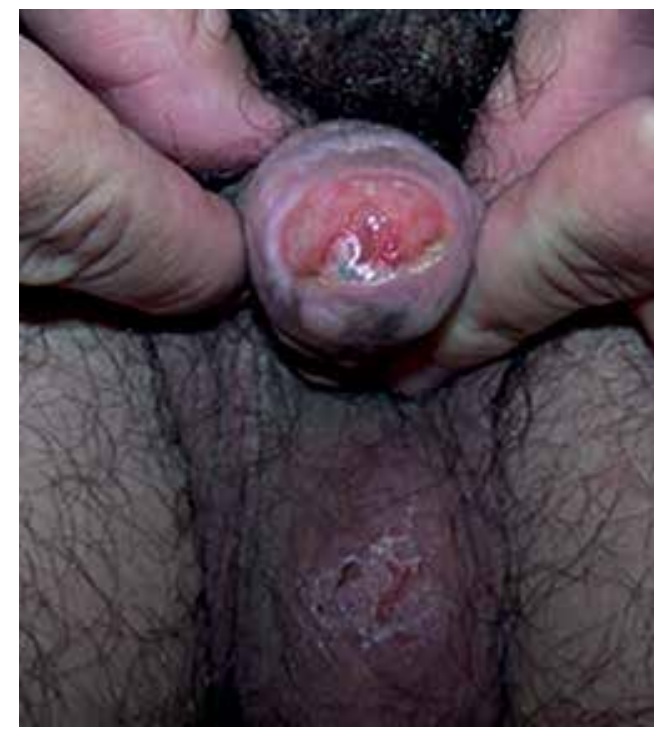

Figure 3: Fifteen days after the first application of 5-fluorouracil 5\% twice daily for two weeks

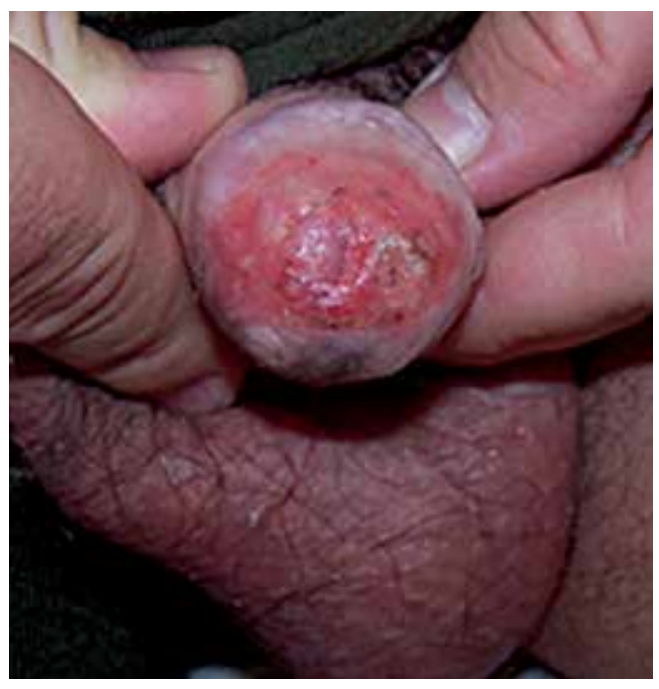

Figure 1:

Initial lesion affecting more than $50 \%$ of the glans

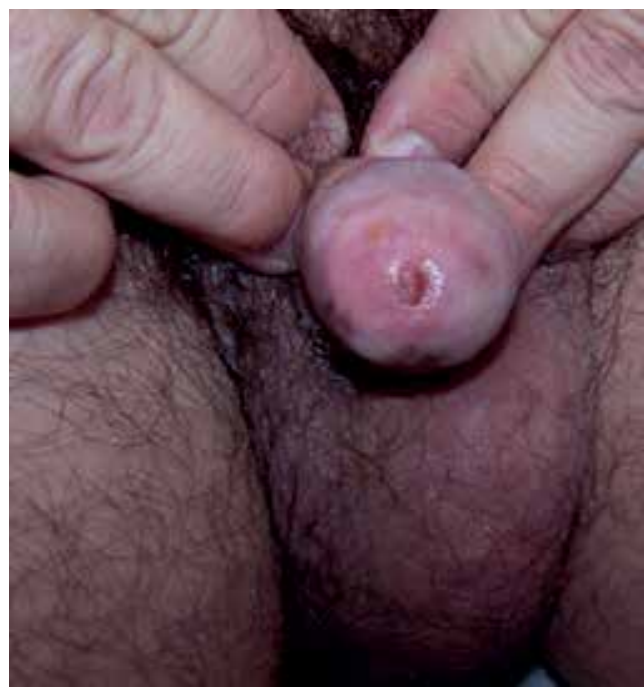

Figure 4:

Fifteen days after the third application of 5-fluorouracil 5\%
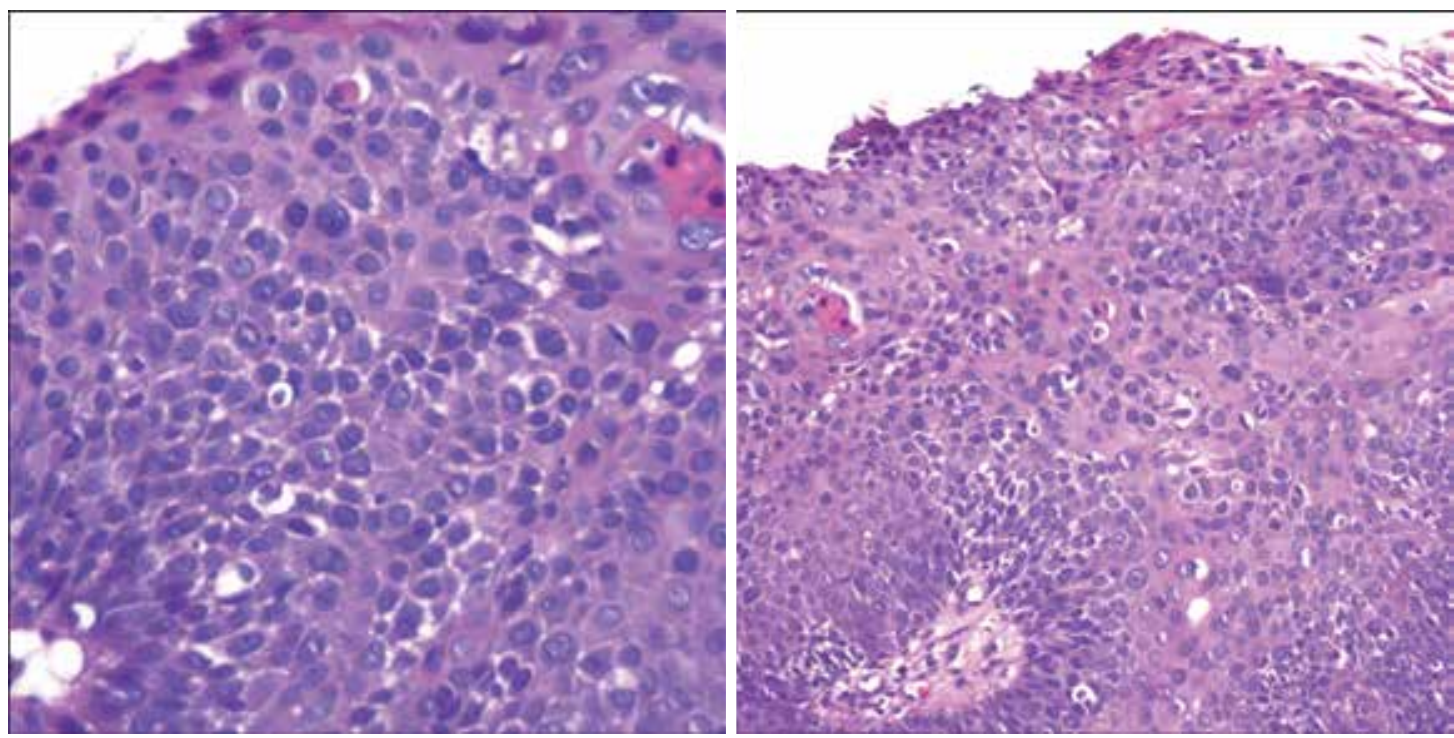

Figure 2:

Initial lesion affecting more than $50 \%$ of the glans 


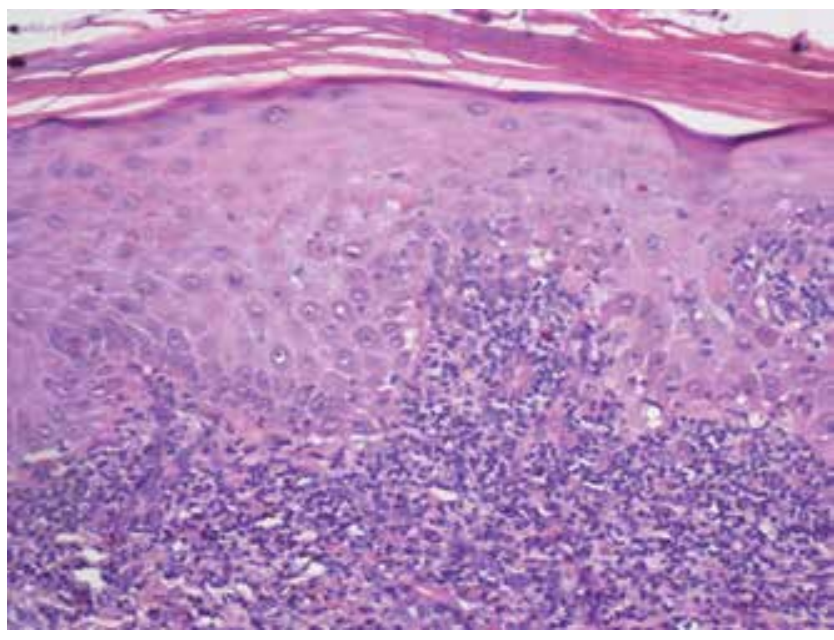

FIGURE 5: Biopsy performed two months after the end of treatment: standard lichenoid interface dermatitis with no atypical cells in the epidermis

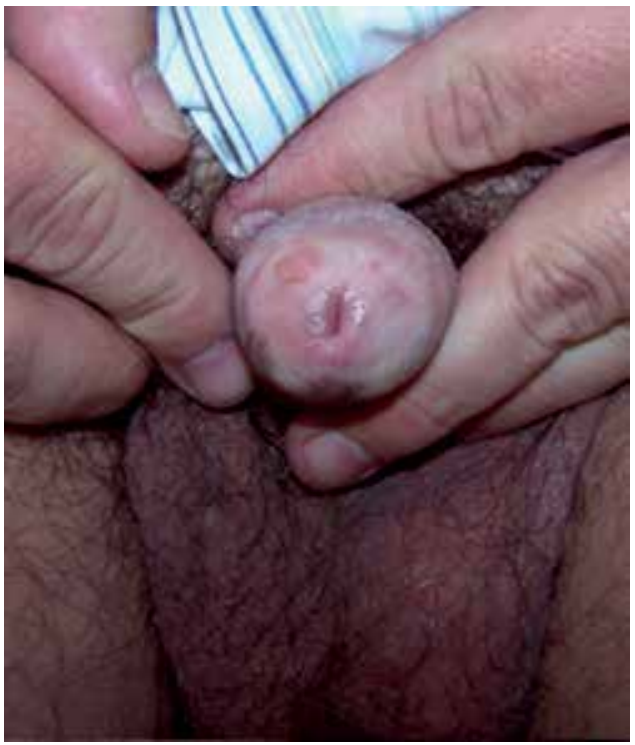

FiguRE 6:

Scar, six months after the end of treatment

\section{REFERENCES}

1. Schmitz L, Bierhoff E, Dirschka T. Optical coherence tomography imaging of erythroplasia of Queyrat and treatment with imiquimod 5\% cream: a case report. Dermatology. 2014;228:24-6.

2. MacKie RM. Epidermal skin tumours. In: Champion RH, Burton JL, Burns DA Breathnach SM, editors. Textbook of Dermatology 6th ed. Vol. 2. Oxford: Blackwell Science; 1998 . p. 1674-5

3. Gerber GS. Carcinoma in situ of the penis. J Urol. 1994;151:829-33.

4. Wieland U, Jurk S, Weissenborn S, Krieg T, Pfister H, Ritzkowsky A. Erythroplasia of Queyrat: coinfection with cutaneous carcinogenic human papillomavirustype 8 and genital papillomaviruses in a carcinoma in situ. $\mathrm{J}$ Invest Dermatol. 2000;115:396-401.

5. Dahlgren S, Nordenstrom B. Transthoracic needle biopsy. Chicago: Year book Medical Publishers, Inc; 1966

6. Yamaguchi Y, Hata H, Imafuku K, Kitamura S, Shimizu H. A case of erythroplasia of Queyrat successfully treated with combination carbon dioxide laser vaporization and surgery. J Eur Acad Dermatol Venereol. 2016;30:497-8.

7. Gambichler T, Jaedicke V, Terras S. Optical coherence tomography in dermatology: technical and clinical aspects. Arch Dermatol Res. 2011;303:457-73.

\section{DISCUSSION}

Since about $33 \%$ of EQ cases become invasive - and the risk of metastases to regional lymph nodes becomes relevant when the tumor invades the submucosa - standard treatment options are usually aggressive..$^{8,9}$

Surgical treatment involving partial or total penectomy should be performed with caution, considering that it is often accompanied by psychological distress, intense emotional distress, and depression. ${ }^{6}$ Thus, the biopsy of the lesion is essential in the therapeutic decision. Physicians must assess the degree of cellular atypia to check if it is restricted to the epidermis, differing EQ from invasive SCC. . $^{1,7}$

In a review paper on the treatment of EQ, Goette concluded that a therapeutic regimen with 5-fluorouracil is associated with high cure rates without evidence of recurrence. ${ }^{10} 5$-fluorouracil acts as an antimetabolite by inhibiting the synthesis of DNA and RNA. The drug can be used continuously for 4-5 weeks and its side effects include erythema, edema, and local irritation. ${ }^{10}$ In the present case, we used a two-week treatment cycle because the patient presented significant local irritation at the end of the second week, which resolved in the interval between the cycles.

By opting for conservative treatment with 5-fluorouracil, continued and prolonged clinical follow-up is fundamental. The results of every therapeutic step should be monitored and attention should be given to the possible evolution of the lesion to invasive SCC.

8. Park JY, Kim SJ, Kim YC. Erythroplasia of Queyrat refractory to photodynamic therapy. Clin Exp Dermatol. 2012;37:795-7.

9. Bonamigo RR, Zampese MS, Bakos L, Pino GD. Eritroplasia de Queyrat e líquen escleroso e atrófico: associação casual ou causal ? An Bras Dermatol. 1995; 70:225-7.

10. Goette DK. Review of erythroplasia of Queyrat and its treatment. Urology. 1976;8:311-5.

MAILING ADDRESS:

João Roberto Antônio

Rua Silva Jardim 3114 - Centro

15010060 - São José do Rio Preto - SP

Brazil

dr.joao@terra.com.br

How to cite this article: Antônio JR, Antônio CR, Trídico LA, Alves FT, Rollemberg I. Erythroplasia of Queyrat treated with topical 5-fluorouracil. An Bras Dermatol. 2016;91(5 Supl 1):S42-4. 